during awake CPAP titration to quantify the effect of chest inflation on the load of the respiratory system.

Patients and methods Obese patients (body-mass-index, BMI >30) with confirmed obstructive sleep apnoea (OSA) were studied and NRD (sEMG $\mathrm{Fara}_{\text {a }}$ ) and the surface EMG of the external oblique $\left(\mathrm{sEMG}_{\mathrm{abd}}\right)$ were recorded and normalised to baseline activity (awake, supine). The apnoea-hypopnoea index (AHI) and $95^{\text {th }}$ percentile of CPAP were determined in sleep studies. The patients were then studied whilst awake and breathing on CPAP (4-20 $\mathrm{cmH}_{2} \mathrm{O}$, increments of $2 \mathrm{cmH}_{2} \mathrm{O} / 3$ mins), with the modified Borg score (mBorg) recorded.

Results 15 patients (age $48 \pm 10$ years, 12 male, BMI $38.9 \pm$ 5.8) suffering with moderate-severe OSA (AHI $32.2 \pm 21.1 / \mathrm{h}$, $95^{\text {th }}$ percentile nocturnal CPAP $\left.14.1 \pm 3.8 \mathrm{cmH}_{2} \mathrm{O}\right)$ were studied. Awake, sEMG $\mathrm{para}_{\text {a }}$ declined by $15.1 \pm 1.5 \%$ from baseline when CPAP was applied, with the nadir at a CPAP of 10.6 $\pm 3.4 \mathrm{cmH}_{2} \mathrm{O}(\mathrm{p}=0.026)$. Further increase in CPAP levels led to a rise in $\mathrm{SEMG}_{\text {para }}$ and breathlessness (mBorg at lowest $\mathrm{sEMG}_{\text {para }} 0.9 \pm 0.8$ points, at CPAP of $20 \mathrm{cmH}_{2} \mathrm{O} 2.7 \pm 2.7$ points, $\mathrm{p}=0.02$ )

Conclusion The respiratory system is maximally offloaded with subtherapeutic CPAP levels in OSA. Levels of NRD observed at effective CPAP levels are associated with breathlessness which can impact on CPAP compliance.

\section{S49 VENTILATORY IRREGULARITY QUANTIFIED BY APPROXIMATE ENTROPY IDENTIFIES DISORDERED BREATHING IN PATIENTS WITH UNEXPLAINED DYSPNOEA}

${ }^{1} \mathrm{~T}$ Bansal, ${ }^{1} \mathrm{GS}$ Haji, ${ }^{2} \mathrm{HB}$ Rossiter, ${ }^{1} \mathrm{Ml}$ Polkey, ${ }^{1} \mathrm{JH}$ Hull. ${ }^{1} \mathrm{NIHR}$ Respiratory Biomedical Research Unit at the Royal Brompton and Harefield NHS Foundation Trust \& Imperial College, London, UK; ${ }^{2}$ Los Angeles Biomedical Research Institute at Harbor-UCLA Medical Center, Torrance, USA

\subsection{6/thoraxjnl-2015-207770.55}

Introduction Patients with idiopathic persistent exertional dyspnoea are often labelled as having a breathing pattern disorder (BPD). There are no agreed objective diagnostic measures for $\mathrm{BPD}$, which complicates its characterisation and response to therapy. Approximate entropy (ApEn) is a measure of unpredictability, based on chaos theorem, which quantifies the degree of irregularity in time-series data.

Objectives To measure ApEn of ventilatory variables during a cardiopulmonary exercise test (CPET) in patients referred with unexplained dyspnoea. We hypothesised that ApEn of tidal volume and breathing frequency would be greater (i.e. more irregular) in patients with BPD than healthy controls.

Methods We studied 20 adults (14 female) with unexplained dyspnoea referred for CPET and diagnosed with BPD (by a senior respiratory physiotherapist blinded to ApEn data) and 15 agegender- and BMI-matched healthy controls. Underlying cardiorespiratory disease was excluded using various investigations (e.g. imaging and echocardiography) prior to referral, in addition to tests performed on the day of CPET; namely pulmonary function and blood gas analysis. ApEn of various ventilatory parameters including tidal volume, breathing frequency and minute ventilation was calculated at rest and during a cycle-ergometer CPET.

Results BPD patients had greater dyspnoea (modified BORG) at rest $(1.4 \pm 1.2$ vs $0.2 \pm 0.6 ; \mathrm{P}<0.01)$ and lower peak oxygen uptake $\left(\mathrm{VO}_{2}\right) \quad(\mathrm{P}<0.01$; Table 1$)$. Peak exercise respiratory exchange ratio was similar between groups $(1.14 \pm 0.17$ vs 1.13 $\pm 0.08, \mathrm{P}=0.84)$ as were nadir values for ventilatory equivalent for $\mathrm{CO}_{2}(28.5 \pm 5.2$ vs $25.5 \pm 3.6, \mathrm{P}=0.07)$ and end-exercise arterial $\mathrm{PCO}_{2}(4.21 \pm 0.68$ vs $4.1 \pm 0.67, \mathrm{P}=$ 0.68). ApEn was significantly greater in the BPD cohort for the duration of the test (Table 1); however differences were not apparent at rest. There was no relationship between ApEn and baseline symptom scores.

Conclusion Measurement of ventilatory ApEn in patients referred with unexplained dyspnoea quantified irregularity of breathing pattern and was significantly greater (more irregular) in BPD than controls. These differences were not apparent from resting phase analysis. Quantifying increased dys-regulation in exercise hyperpnoea using ApEn can be applied to ventilatory variables collected during standard CPET, and thus could aid in diagnosis and evaluating treatment response in BPD. Further work should explore how ventilatiory ApEn relates to perception of symptoms.

\begin{tabular}{|c|c|c|}
\hline & BPD $(N=20)$ & Healthy Controls $(\mathrm{N}=15)$ \\
\hline Age (years) & $49(14)$ & $50(18)$ \\
\hline BMI $\left(\mathrm{kg} / \mathrm{m}^{2}\right)$ & $26.0(5.0)$ & $24.5(3.7)$ \\
\hline $\mathrm{FEV}_{1}$ (\% predicted) & $107(18)$ & $95(18)^{*}$ \\
\hline $\mathrm{FEV}_{1} / \mathrm{FVC}$ & $0.78(0.06)$ & $0.75(0.12)$ \\
\hline $\mathrm{VO}_{2} / \mathrm{kg}$ Peak $(\mathrm{ml} / \mathrm{min} / \mathrm{kg})$ & $20.7(7.1)$ & $37.9(14.9)^{* *}$ \\
\hline $\mathrm{VO}_{2}$ Peak (\% Predicted) & $79.8(17.5)$ & $124.8(27.3)^{* *}$ \\
\hline ApEn Tidal Volume & $1.31(0.23)$ & $1.04(0.28)^{* *}$ \\
\hline ApEn Breathing Frequency & $1.42(0.22)$ & $1.24(0.24)^{*}$ \\
\hline ApEn Minute Ventilation & $1.01(0.29)$ & $0.64(0.22)^{* *}$ \\
\hline
\end{tabular}

\section{S50 UNDERSTANDING HEROIN OVERDOSE: A STUDY OF THE ACUTE RESPIRATORY DEPRESSANT EFFECTS OF INJECTED PHARMACEUTICAL HEROIN}

${ }^{1} \mathrm{CJ}$ Jolley, ${ }^{1} \mathrm{~J}$ Bell, ${ }^{1} \mathrm{GF}$ Rafferty, ${ }^{1} \mathrm{~J}$ Moxham, ${ }^{2} \mathrm{~J}$ Strang. ${ }^{1}$ King's College London, London, UK; ${ }^{2}$ South London \& Maudsley NHS Foundation Trust, London, UK

\subsection{6/thoraxjnl-2015-207770.56}

Introduction and objectives Opioids are respiratory depressants and heroin/opioid overdose is a major contributor to the excess mortality of heroin addicts. The individual and situational variability of respiratory depression caused by intravenous heroin is poorly understood. The aim of this study was to use advanced physiological monitoring to follow the time course and severity of acute opioid-induced respiratory depression.

Methods 10 patients (9/10 with chronic airflow obstruction) undergoing supervised injectable opioid treatment for heroin addiction received their usual prescribed dose of injectable opioid (diamorphine or methadone) (IOT), and their usual prescribed dose of oral opioid (methadone or sustained release oral morphine) after $30 \mathrm{~min}$. The main outcome measures were pulse oximetry $\left(\mathrm{SpO}_{2} \%\right)$, end-tidal $\mathrm{CO}_{2} \%\left(\mathrm{ETCO}_{2} \%\right)$ and neural respiratory drive (NRD) (quantified using parasternal intercostal muscle electromyography). Significant respiratory depression was defined as absence of inspiratory airflow $>10$ s, $\mathrm{SpO}_{2} \%<90 \%$ for $>10$ s and $\mathrm{ETCO}_{2} \%$ per breath $>6.5 \%$.

Results $\mathrm{ETCO}_{2} \%$ indicated significant respiratory depression following IOT in $8 / 10$ patients, with levels increasing from baseline 4.7 (4.5 to 5.4$) \%$ to 5.4 (5.1 to 5.7$) \%$ at $30 \mathrm{~min}, \mathrm{p}=0.01$. The median (range) peak $\mathrm{ETCO}_{2} \%$ per breath was $6.9 \%$ (5.2 to 7.8 ). 
In contrast, $\mathrm{SpO}_{2} \%$ indicated significant respiratory depression in only 4/10 patients, with small absolute changes in $\mathrm{SpO}_{2} \%$ from 96.5 (95.1 to 99.2$) \%$ at baseline to $96.2(95.2$ to $97.0 \%)$ at 30 min. A non-significant decline in NRD from baseline (109.5 (69.5 to 185.1 ) a.u.) to $30 \mathrm{~min}$ post IOT 84.3 (59.2 to 118.1 ) a.u., $\mathrm{p}=$ 0.12) was also observed. Baseline NRD and opioid-induced drop in $\mathrm{SpO}_{2} \%$ were inversely related $(\mathrm{r}=-0.67, \mathrm{p}=0.04)$.

Conclusion Significant acute respiratory depression is commonly induced by opioid drugs prescribed to treat opioid addiction. Hypoventilation is reliably detected by capnography, but not by $\mathrm{SpO}_{2} \%$ alone. Chronic suppression of NRD in the presence of underlying lung disease may be a risk factor for acute opioidinduced respiratory depression.

\section{S51 ARTERIAL OXYGEN CONTENT REFLECTS HAEMOGLOBIN MORE THAN OXYGENATION INDICES IN 440 PATIENTS WITH PULMONARY ARTERIOVENOUS MALFORMATIONS}

${ }^{1} \mathrm{CL}$ Shovlin, ${ }^{2} \mathrm{~B}$ Chamali, ${ }^{2} \mathrm{~V}$ Santhirapala, ${ }^{3} \mathrm{~L}$ Williams, ${ }^{3} \mathrm{E}$ Jackson, ${ }^{3} \mathrm{H}$ Tighe. ${ }^{1} / \mathrm{mperial}$

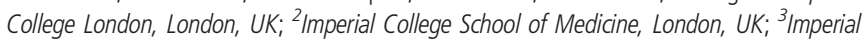
College Healthcare NHS Trust, London, UK

\subsection{6/thoraxjnl-2015-207770.57}

Introduction and objectives Our goal was to use a long term model of human hypoxaemia to evaluate factors that reduce arterial oxygen content $\left(\mathrm{CaO}_{2}\right)$ and therefore demand higher cardiac outputs to maintain tissue oxygen delivery. This is important for clinical practice; for clinical trials that use cardiac index as a primary outcome measure; and particularly relevant for patients with pulmonary and systemic arteriovenous malformations (AVMs) due to hereditary haemorrhagic telangiectasia (HHT).

Methods Presentation data were evaluated on 497 consecutive patients with pulmonary AVMs due to HHT, reviewed between 1999 and 2013. $\mathrm{SaO}_{2}$ was measured by pulse oximetry in the supine and erect postures, and the mean $\mathrm{SaO}_{2}$ calculated after 7 , 8,9 and 10 min standing. Same-day haemoglobin was measured in venous blood samples in 440 patients. Presentation $\mathrm{CaO}_{2}$ was calculated by the equation oxygen saturation $\left(\mathrm{SaO}_{2}, \%\right) x$ haemoglobin $(\mathrm{gram} / \mathrm{dL}) \times 1.34 / 100$.

Results There was a four-fold difference in $\mathrm{CaO}_{2}$ across the 440 patients (range 7.6-27.5, median 17.6) mls of oxygen per decilitre (dL) of arterial blood. $\mathrm{SaO}_{2}$ ranged from $59-100 \%$ (median $94.8 \%$ ), but $\mathrm{CaO}_{2}$ did not change appreciably across the $\mathrm{SaO}_{2}$ quartiles (median $\mathrm{CaO}_{2}$ 17.1; 18.1; 17.7; $17.8 \mathrm{mls} / \mathrm{dL} ; \mathrm{p}=$ 0.34 , Figure $1 \mathrm{~A})$. In contrast, $\mathrm{CaO}_{2}$ was primarily determined by haemoglobin which ranged from 5.9-21.8 g/dL (median $14.1 \mathrm{~g} /$ $\mathrm{dL}$ ). The median $\mathrm{CaO}_{2}$ across quartiles of haemoglobin were 14.1; 16.7, 18.5; and $20.5 \mathrm{mls} / \mathrm{dL}$ ( $<<0.0001$, Figure 1B). For each $1 \mathrm{~g} / \mathrm{dL}$ rise in haemoglobin, there was a $10 \%$ increase in mls of oxygen per unit blood volume.
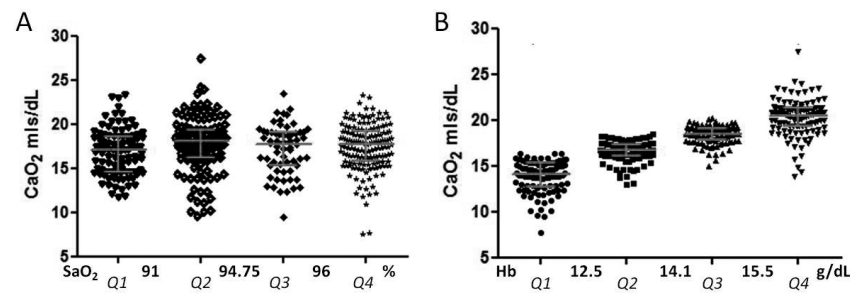

Abstract S51 Figure 1 Distribution of arterial oxygen content $\left(\mathrm{CaO}_{2}\right)$ across the quartiles of $\mathrm{A}$ ) oxygen saturation $\left(\mathrm{SaO}_{2}\right)$, and $\mathrm{B}$ ) haemoglobin $(\mathrm{Hb})$ in 440 patients with pulmonary AVMs
Conclusions Currently, in long term conditions, more attention is paid to modest differences in $\mathrm{SaO}_{2}$ than to haemoglobin. ${ }^{1} \mathrm{It}$ has been shown that patients with PAVMs maintain $\mathrm{CaO}_{2}$, and deliver the same amount of oxygen per heart beat (oxygen pulse) before and after correction of hypoxaemia by PAVM embolisation. ${ }^{2,3}$ For patients where higher cardiac outputs may be detrimental, further attention should be given to minor incremental falls in haemoglobin that substantially reduce arterial oxygen content.

\section{REFERENCES}

1 Hardinge $\mathrm{M}$, Annandale J, Bourne $\mathrm{S}$, et al. BTS guidelines for home oxygen use in adults. Thorax 2015:70:i1-i43

2 Santhirapala V, Williams LC, Tighe HC, et al. Arterial oxygen content is precisely maintained by graded erythrocytotic responses in settings of high/normal serum iron levels, and predicts exercise capacity: an observational study of hypoxaemic patients with pulmonary arteriovenous malformations. PLOS One 2014;9(3): e90777

3 Howard L, Santhirapala V, Murphy K, et al. Chest 2014;146(3):709-18

\section{S52 THE EFFECT OF AGE ON ARTERIAL OXYGEN CONTENT IN PATIENTS WITH PULMONARY ARTERIOVENOUS MALFORMATIONS (PAVMS)}

${ }^{1}$ AF Rizvi, ${ }^{2}$ L Babawale, ${ }^{2} \mathrm{JMB}$ Hughes, ${ }^{2} \mathrm{JE}$ Jackson, ${ }^{3} \mathrm{CL}$ Shovlin. ${ }^{1}$ Imperial College School of Medicine, London, UK; ${ }^{2}$ Imperial College Hospital NHS Trust, London, UK; ${ }^{3}$ Imperial College London, London, UK

\subsection{6/thoraxjnl-2015-207770.58}

Introduction and objectives It is recognised that age-associated changes in the chest wall and lung parenchyma lead to decreased efficiency of ventilation and gas exchange, resulting in reduced arterial partial pressure of oxygen $\left(\mathrm{PaO}_{2}\right)$ and haemoglobin saturation $\left(\mathrm{SaO}_{2}\right)$. The total oxygen content of arterial blood $\left(\mathrm{CaO}_{2}\right)$ depends upon $\mathrm{SaO}_{2}$, as well as haemoglobin concentration. Our goal was to examine serial changes in arterial oxygen content with age in a cohort with hypoxaemia due to pulmonary arteriovenous malformations (PAVMs).

Methods Retrospective longitudinal follow-up data was collected for 100 consecutive PAVM patients presenting to a tertiary care institutional clinic between 1984 and 2001, and reviewed until 2015. Subjects provided up to 30 (median 9) separate annual datasets. $\mathrm{SaO}_{2}$ was measured by pulse oximetry in the supine and erect postures, and the mean $\mathrm{SaO}_{2}$ was calculated after 7, 8, 9 and 10 min standing. Haematological and biochemical blood indices evaluated haemoglobin, haematinics, and iron indices. $\mathrm{CaO}_{2}$ in $\mathrm{mls}$ of oxygen per $\mathrm{dL}(\mathrm{ml} / \mathrm{dL})$ of blood was calculated using the equation: $\left[\mathrm{SaO}_{2}(\%) x\right.$ haemoglobin $(g / d L) X 1.34] / 100$. Data were analysed using STATA IC v13.1.

Results Age and PAVM-treatment associated changes in $\mathrm{SaO}_{2}$ were mostly accompanied by opposing changes in haemoglobin levels that maintained the $\mathrm{CaO}_{2}$. Two major patterns were observed. The first was the expected increase in haemoglobin with lower $\mathrm{SaO}_{2}$, due to secondary erthyrocytosis and polycythaemia. The second, less well recognised, was an increase in $\mathrm{SaO}_{2}$ when haemoglobin fell, most commonly when subjects developed iron deficiency and anaemia. Nevertheless, excluding participants with iron deficiency, $\mathrm{CaO}_{2}$ decreased with age (Figure $1, \mathrm{r}^{2}=-0.0654 ; \mathrm{p}<0.001$, Figure 1). 